\title{
Cambios de uso del suelo y crecimiento urbano. Estudio de caso en los municipios conurbados de la Mancomunidad Metrópoli de Los Altos, Quetzaltenango, Guatemala
}

Changes in land use and urban growth. Case study in the neighboring municipalities of the Commonwealth Metrópoli de Los Altos, Quetzaltenango, Guatemala

Héctor Obdulio Alvarado-Quiroa'

Freddy Araya-Rodríguez ${ }^{2}$

Fecha de recepción: 27 de junio del 2013

Fecha de aprobación: 18 de agosto del 2013

Alvarado-Quiroa, $\mathrm{H}$; Araya-Rodríguez, F.

Cambios de uso del suelo y crecimiento urbano. Estudio de caso en los municipios conurbados de la Mancomunidad Metrópoli de Los Altos, Quetzaltenango, Guatemala.

Tecnología en Marcha. Vol. 27, Nº I. Pág I04-1 13

Ingeniero Agrónomo en Sistemas de Producción Agrícola, MSc. en Gerencia de la Agricultura Sostenible y los Recursos Naturales, MSc. en Administración de Tierras para el Desarrollo Sostenible, estudiante del Doctorado en Ciencias Naturales para el Desarrollo Sostenible. Profesor de la División de Ciencia y Tecnología del Centro Universitario de Occidente de la Universidad de San Carlos de Guatemala. Teléfono: (502)54l 61669. Correo electrónico: hectoralvarado@cytcunoc.org.

2 Profesor/Investigador, Instituto Tecnológico de Costa Rica. Costa Rica. Teléfono: 240I-3140. Correo electrónico: faraya@itcrac.cr. 


\section{Palabras clave}

Cambios de uso del suelo; intensidad de uso del suelo; crecimiento urbano; ordenamiento territorial.

\section{Resumen}

Para la planificación estratégica territorial es indispensable elaborar diagnósticos territoriales que develen el comportamiento y las dinámicas, es decir, analizar las relaciones mutuas entre la vocación de uso de la tierra (capacidad de uso) y su uso actual. El presente artículo hace un análisis de los cambios de uso y el crecimiento urbano que ha sufrido el territorio de los municipios conurbados de la Metrópoli de Los Altos, en el departamento de Quetzaltenango, Guatemala, como un indicador de la intensidad de uso de territorio. Para ello se determinó en primera instancia la capacidad de uso del suelo, utilizando la metodología del INAB (2000). Al determinar la capacidad de uso y contrastarlo con el uso dado para los años 1964, 1970, 1982, 1990, 2002 y 2006, se explica cómo a partir del año 1990 y hasta 2006 empieza a darse una alta conflictividad (intensidad) en el uso del territorio.

Con este estudio se demuestra la presión que ha ejercido la expansión urbana sobre los suelos con una alta vocación agrícola y sobre el medio natural, especialmente sobre las áreas protegidas y bosques, debido a la falta de una planificación estratégica territorial. Esto ha provocado un uso espontáneo del territorio y un crecimiento urbano descontrolado con graves repercusiones ambientales. En el estudio también se estima el escenario tendencial, dando como resultado la desaparición de toda el área con alta vocación agrícola para el año 2039.

\section{Key words}

Changes in land use; land use intensity; urban growth; territorial planning.

\begin{abstract}
For territorial strategic planning there is an essential need for territorial diagnostics that reveal the behavior and dynamics of it and to analyze the interrelationships between the vocation of the land use (ability of land use) and its current use. This article analyzes the changes in the land use and urban growth that the territory of the neighboring municipalities of the Metropolis of the Commonwealth of Los Altos, Quetzaltenango, Guatemala, has undergone from 1964 to 2010 , as an indicator of land use intensity. For this matter, the ability of land use was first established using the methodology from INAB (2000). By determining the usability and contrasting it with the use in the years 1964, 1970, 1982, 1990, 2002 and 2006, it is explained how from the year 1990 to 2006, it begins to show high conflict (intensity) in the land use. This study demonstrates the pressure exerted by urban sprawl on soils with high agricultural potential and on the environment, especially on protected areas and forests due to the lack of a strategic territorial planning, which has caused a spontaneous use of the territory and an uncontrolled urban sprawl with high environmental impact. The study also estimated the trend scenario, in other words, what could happen if things continue behaving like the have so far, resulting in the disappearance of the entire area with high agricultural potential by the year 2039.
\end{abstract}




\section{Introducción}

La jerarquización de los conflictos por el uso de la tierra permite identificar prioridades para el ordenamiento territorial y constituye la base para determinar los tipos de usos alternativos que pueden dársele al territorio, por ello son necesarios para la formulación e implementación de Planes Estratégicos Territoriales que contribuyan a su desarrollo sostenible.

La gestión territorial del espacio rural y urbano en Guatemala, especialmente lo que tiene que ver con su ordenamiento, es una responsabilidad de las municipalidades. Éstas deben ejercer un control sobre la utilización de los territorios tanto públicos como privados, pero hasta ahora han hecho muy poco o nada para controlar la expansión urbana, lo cual repercute en forma negativa en las áreas de vocación agrícola, forestales y protegidas; estas últimas tan importantes por los servicios ambientales que generan.

En la ciudad de Quetzaltenango, en particular, y en los municipios conurbados que pertenecen a la Mancomunidad Metrópoli de Los Altos (para este estudio conformada por los municipios de Quetzaltenango, Salcajá, La Esperanza, Olintepeque y San Mateo), se ha experimentado una alta demanda de espacios inducida por procesos acelerados de crecimiento de la población, altas tasas de concentración poblacional en centros urbanos, inmigración y especulación inmobiliaria; el resultado es que han crecido en forma discontinua, desarticulada, y extensiva.

El espacio que hasta 1997 tenía un uso exclusivamente agrícola en el Valle de Quetzaltenango actualmente ha dado paso a la construcción de viviendas, comercio e industria, tanto formal como informal. Este crecimiento acelerado y desordenado está provocando un cambio en el uso de la tierra, sin considerar las características (vocación) de los suelos, sus limitaciones, potencialidades y distribución geográfica, ocasionando un fuerte impacto ambiental, social y económico al desplazar la actividad agrícola a suelos marginales y/o suelos con vocación forestal y protección, originando así conflictos por el uso del suelo.

La intensidad de uso del territorio se define como la determinación y cuantificación de la extensión y distribución geográfica, en un período de tiempo determinado, de la idoneidad del uso del territorio de acuerdo con su uso potencial. Mide la tendencia de transformación del uso óptimo del territorio a un tipo de uso no idóneo, proporcionando información sobre el estado real de la aplicación de políticas de ordenamiento territorial. La intensidad (o conflictos) de uso del territorio es un indicador que provee información para solucionar numerosos problemas relacionados con la tierra, la degradación y la conservación de suelos y aguas, así como también problemas relacionados con las políticas sobre manejo sostenible, ya que define el grado de compatibilidad del territorio de acuerdo con su capacidad de uso potencial.

\section{Materiales y métodos}

Para hacer el análisis de los cambios de uso del suelo se utilizaron fotografías aéreas correspondientes a los años 1964, 1970, 1982 y 1990 y las ortofotos de 2002 y 2006 obtenidas en el Instituto Geográfico Nacional de Guatemala (IGN). Las fotografías aéreas de 1964, 1970, 1980 y 1990, que se encuentran en formato análogo, se escanearon en tonos de grises, obteniendo imágenes digitales en formato "tiff" con una resolución de 10 micras por "pixel". Una vez generadas las ortofotos a través del software "DIGI3D", se procedió a la rectificación de las imágenes digitales con el apoyo de un Modelo Digital del Terreno, realizado con curvas a nivel distanciadas a $20 \mathrm{~m}$. Con las imágenes digitales rectificadas, se utilizó el software "Arc Gis 9.I" para reconocer e identificar los diferentes usos de suelo a través de la diferencia de tonalidades, es decir, el cambio de grises.

Una vez identificadas las entidades, es decir, los usos de suelo, se procedió a realizar una fotointerpretación, donde en primera instancia en la plataforma de "Arc Catalog" se generó una figura ("shape") de tipo de entidad Polígono en el sistema de referencia WGS 84 UTM Zona 15. Seguidamente se procedió a la delineación de entidades (o digitalización), para lo cual se utilizaron las herramientas de tarea de "Arc Map" de tal forma que no quedaran áreas sin digitalizar.

Al obtener las figuras (shapes), se generó en la tabla de atributos un campo denominado "Áreas", en donde se calculó el área a través de la herramienta "Calculate Geometry" (cálculo de geometría) en 
"Arc Map". La etapa anterior generó seis mapas de uso actual correspondiente a los años 1964, 1970, 1978, 1990, 2002 y 2006. Estos mapas sirvieron de base para discutir las variables de estudio. A través de las etapas anteriores con el Software "ArcGis 9. I" se pudo cuantificar el área para cada uno de los usos del suelo, incluyendo los centros poblados, para cada uno de los años de referencia. Se realizó el análisis del crecimiento urbano, definiendo el incremento del área en el período de estudio, así como un análisis de correlación múltiple, para elaborar un modelo del crecimiento tendencial de los centros poblados para los años 2014, 2024 y 2034.

El indicador de "Intensidad de Uso del Territorio" se basó en el análisis biofísico realizado mediante las variables "uso actual del territorio" y "capacidad de uso", determinándose las divergencias entre el uso potencial de un territorio (basado en su aptitud y vocación natural) que puede ser practicado sin riesgo de deteriorar el suelo, y el uso actual que se hace del territorio en cuestión. Para evaluar los conflictos de uso de la tierra se hizo un análisis comparativo de la capacidad de uso del suelo (de acuerdo con la metodología del INAB, 2000) con el uso actual, a través de una matriz de análisis de conflictos de uso del suelo, dándoles una calificación apreciativa (usos adecuado, sobreuso y subuso) en función de cada tipo de tierra presente en cada municipio.

\section{Análisis y discusión}

\section{Capacidad de uso del suelo de} los municipios conurbados de la mancomunidad metrópoli de los altos

La capacidad de uso del suelo generalmente se basa en el principio de la máxima intensidad de uso soportable sin causar deterioro físico del suelo, es decir, se refiere solo a un nivel máximo de aplicación del recurso suelo sin que este se deteriore, con una tasa más grande que la tasa de su formación. La clasificación de tierras por capacidad de uso es un agrupamiento de interpretaciones que se hacen principalmente para fines agrícolas y comienza por la distinción de las unidades de mapeo. Permite hacer algunas generalizaciones con respecto a las potencialidades del suelo, limitaciones de uso y problemas de manejo. La capacidad de uso del suelo del área de estudio se realizó de acuerdo con la metodología propuesta por el Instituto Nacional de Bosques (INAB, 2000; esta capacidad de uso potencial se presenta en el cuadro I.

Como puede apreciarse en dicho cuadro, del área total de estudio, el $20 \%$ es de vocación forestal de protección; esta categoría presenta áreas con limitaciones severas en cualquiera de los factores limitantes o modificadores, son apropiadas para actividades forestales de protección o conservación ambiental exclusiva, son tierras marginales para uso agrícola o pecuario intensivo. Tienen como objetivo preservar el ambiente natural, conservar la biodiversidad, así como las fuentes de agua. Estas áreas permiten la investigación científica y el uso ecoturístico en ciertos sitios habilitados para tales fines, sin que esto afecte negativamente los ecosistemas presentes en ellas. También se incluyen las áreas sujetas a inundaciones frecuentes y otros ecosistemas frágiles. Esta categoría también incluye las zonas denominadas bosques ribereños, que son áreas ubicadas en las márgenes de los ríos, riachuelos o quebradas y en los nacimientos de agua. Sus funciones son retener sedimentos que proceden de las partes altas, proteger los cauces y espejos de agua y la captación del agua de lluvia, a través de la parte aérea de la vegetación existente. Esta área puede ubicarse en el territorio en estudio en el Cerro El Baúl, Cerro Quemado, volcán Santa María, volcán Siete Orejas y ribera del río Samalá y sus afluentes.

Cuadro I. Clasificación de tierras por capacidad de uso en la Mancomunidad Metrópoli de Los Altos.

\begin{tabular}{|l|c|c|}
\hline Categorías de capacidad de uso & Hectáreas & $\%$ \\
\hline Agricultura con mejoras & 774,48 & 4.09 \\
\hline Agricultura sin limitaciones & 8124,29 & 42.94 \\
\hline $\begin{array}{l}\text { Agroforestería con } \\
\text { cultivos anuales }\end{array}$ & 3128,04 & 16.53 \\
\hline $\begin{array}{l}\text { Agroforestería con cultivos } \\
\text { permanentes }\end{array}$ & 171,77 & 0,91 \\
\hline Sistemas silvopastoriles & 102,53 & 0,54 \\
\hline Tierras forestales de producción & 2887,94 & 15,26 \\
\hline Tierras forestales de protección & 3729,95 & 19,73 \\
\hline \multicolumn{1}{|c|}{ TOTAL } & 18919,00 & 100,00 \\
\hline
\end{tabular}

Fuente: Investigación de campo 2010. 
Otro 15\% del área se ubica en la categoría de manejo forestal de producción. Se trata de áreas con limitaciones para usos agropecuarios, de pendiente o pedregosidad, con aptitud preferente para realizar un manejo forestal sostenible, tanto del bosque nativo como de plantaciones con fines de aprovechamiento, sin que esto signifique el deterioro de otros recursos naturales. La sustitución del bosque por otros sistemas conllevaría la degradación productiva de los suelos. Esta categoría se ubica contigua a la de tierras forestales de protección. Las dos categorías anteriores abarcan un total de 6 617,89 hectáreas (35\%) del área de estudio y por la función ambiental que realizan, en ellas no debería permitirse el cambio de uso de la tierra.

Por otro lado, en el cuadro I también se aprecia que para casi el 43\% del área de estudio (8 I 24,29 ha) la vocación del suelo debería ser para una agricultura sin limitaciones. Lo anterior denota el potencial de la zona de estudio para la producción agrícola de una forma intensiva, pero como se describirá más adelante, esta área se ha ido perdiendo para darle paso a la expansión urbana.

\section{Cambios de uso del territorio en el área de estudio a partir del año 1964}

Durante los 42 años que separan la fecha inicial y final de la presente investigación, se notan las profundas modificaciones que ha experimentado el entorno metropolitano de la ciudad de Quetzaltenango y los municipios conurbados que la constituyen. Se ha identificado en el territorio una importante dinámica de cambio de los usos del suelo, en donde el crecimiento del área urbana en detrimento del suelo de vocación agrícola, forestal y áreas protegidas es uno de los hechos más significativos.

El análisis de los cambios de uso del territorio se hacen en función de las áreas protegidas, áreas forestales, áreas agrícolas y el crecimiento urbano del área de estudio (ver cuadro 2).

\section{Cambios de uso del territorio en las áreas protegidas}

El análisis de los cambios de uso se inicia con las áreas protegidas que han sido declaradas, por decreto gubernativo, dentro de la zona de estudio. De acuerdo con la información que aporta el cuadro 2 , podemos apreciar que el área total dedicada a ésta permanece sin variaciones durante el período de estudio y ello se debe a que todas las áreas protegidas fueron declaradas como tales antes de 1964 y no se ha declarado ninguna nueva. Sin embargo, a través de la fotointerpretación puede apreciarse que sí han existido cambios de uso del suelo dentro de ellas, especialmente por el avance de la frontera agrícola, lo que por supuesto es ilegal dada su categoría de áreas protegidas.

Pero también en los últimos años han existido cambios de uso provocados por la expansión urbana, tales son los casos del cerro El Baúl (desde hace más de 10 años) y recientemente el del cerro Siete Orejas, con la creación de la Nueva Ciudad de Los Altos. Podemos decir que estas zonas habitaciona-

Cuadro 2. Cambios de uso del suelo durante el periodo 1964-2006 en el área de estudio.

\begin{tabular}{|c|c|c|c|c|c|c|c|c|c|c|c|c|}
\hline & \multicolumn{10}{|c|}{ Año } \\
\hline & \multicolumn{2}{|c|}{1964} & \multicolumn{2}{|c|}{1970} & \multicolumn{2}{|c|}{1982} & \multicolumn{2}{|c|}{1990} & \multicolumn{2}{c|}{2002} & 2006 \\
\hline Uso & ha & $\%$ & ha & $\%$ & ha & $\%$ & ha & $\%$ & ha & $\%$ & ha & $\%$ \\
\hline Protegida & 3096 & 16,4 & 3096 & 16,4 & 3096 & 16,4 & 3096 & 16,4 & 3096 & 16,4 & 3096 & 16,4 \\
\hline Agrícola & 9753 & 51,5 & 9591 & 50,7 & 9509 & 50,2 & 8703 & 46,0 & 7621 & 40,3 & 5471 & 28,9 \\
\hline Forestal & 5221 & 27,6 & 5044 & 26,7 & 4809 & 25,4 & 4585 & 24,2 & 3793 & 20,0 & 3747 & 19,8 \\
\hline Urbana & 849 & 04,5 & 1188 & 06,3 & 1505 & 08,0 & 2535 & 13,4 & 4409 & 23,3 & 6605 & 34,9 \\
\hline TOTAL & 18919 & 100 & 18919 & 100 & 18919 & 100 & 18919 & 100 & 18919 & 100 & 18919 & 100 \\
\hline
\end{tabular}

Fuente: Información de campo 2010. 


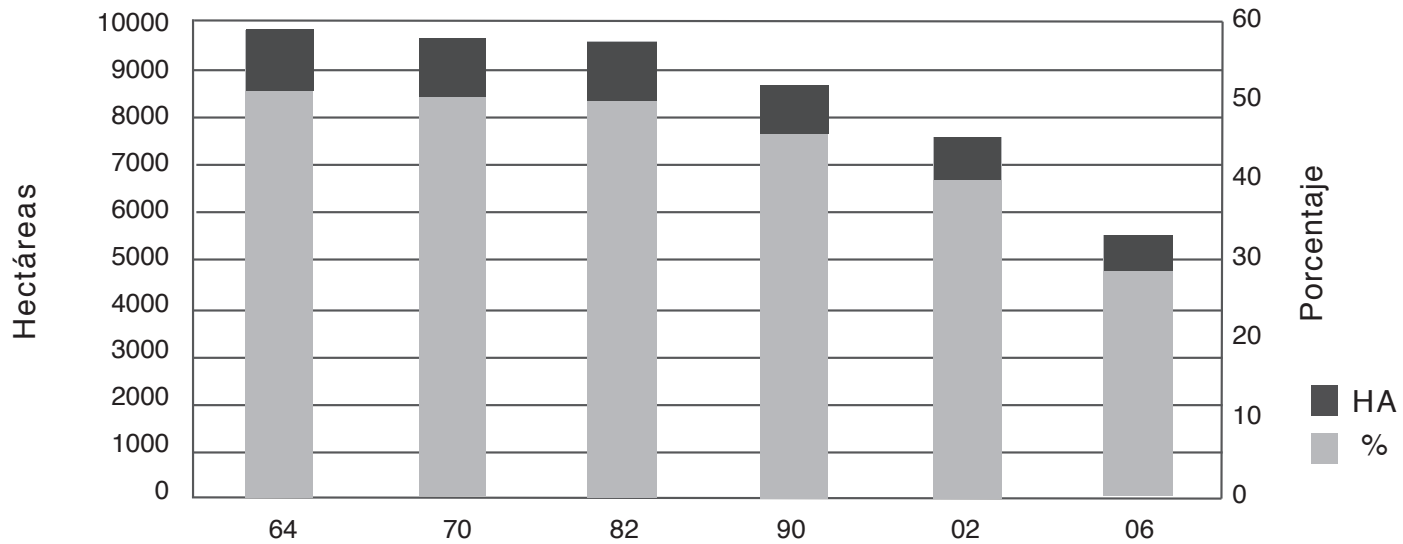

Figura I. Reducción del uso agrícola durante el periodo 1964-2006 en el área de estudio.

Fuente: Investigación de campo 2009.

les, además de situarse en áreas de alto riesgo por deslaves, erosión y suelo con poca capacidad de soporte para la construcción de viviendas y edificios en general, han reducido la capacidad de recarga hídrica de Quetzaltenango, algo muy importante si remarcamos que la ciudad depende en un $75-80 \%$ de los mantos freáticos para su abastecimiento de agua. Lo anterior también provoca inconvenientes como azolvamientos, deslaves e inundaciones, como el caso que se da en el Barrio El Calvario, especialmente en la cuarta calle de la zona I y la zona 2 de Quetzaltenango.

No pudo cuantificarse la pérdida de área para cada uno de los años de estudio, ya que el cambio de uso ha sido disperso; sin embargo, el área total invadida entre 1964 y 2006 es de 724.77 ha. Esto denota el poco control que las autoridades responsables de las áreas protegidas tienen sobre ellas, a pesar de que la legislación vigente dispone de una serie de medidas legales para evitar el cambio de uso. Las áreas invadidas por actividades agrícolas y urbanas se encuentran en el cerro El Baúl y el volcán Siete Orejas y, para el caso del volcán Santa María, el cambio de uso ha sido especialmente con fines agrícolas.

\section{Cambios del uso del territorio con vocación agrícola}

Si comparamos la información del cuadro I, donde se presenta la capacidad de uso del suelo para la zona en estudio, el área con potencial agrícola es de 8 898,77 ha (equivalente al 47,03\%). De acuerdo con la fotointerpretación realizada para el año 1964 , existía una alta correspondencia entre la capacidad de uso potencial y el uso dado, el cual representaba el 5I,5\% del área total de estudio; por lo que puede inferirse que no existían para ese año conflictos de uso. Seis años después (1970), el área agrícola se redujo en un I,7\% (I 62 ha) y representaba el 50,7\% del área total. Para 1980 la reducción había alcanzado el 2,5\% (se perdieron 244 ha destinadas a actividades agrícolas), con respecto a 1964 (ver figura I).

El cambio de uso de suelo de agrícola a urbano ocurrido entre 1964 y 1982 puede considerarse una reducción normal debido al crecimiento de la población, ya que el incremento del área urbana en estos 18 años es solo de 656 ha (el 3,5\%) y el decremento de las áreas agrícolas y forestal fue de 244 ha y 412 ha $(1,3 \%$ y $2,2 \%)$ respectivamente. Durante este período, de acuerdo con la fotointerpretación realizada, el uso forestal, con un $2,2 \%$, es el que más aportó al crecimiento urbano; y el uso agrícola, con un 1,3\%. La pérdida de área boscosa y área con fines agrícolas se da casi con exclusividad para la ciudad de Quetzaltenango, donde desaparecen las áreas que están contiguas al núcleo urbano, especialmente en la parte occidental (lo que hoy es la Colonia Minerva y la Colonia El Cervecero); hacia el sur se forma la Colonia Molina. Hacia el norte, la ciudad no sobrepasa el río Seco y hacia el oriente, la ciudad no llegaba a lo que hoy es el monumento a la Marimba. Hay muy poco crecimiento urbano en los otros municipios en estudio.

Otra información que es relevante discutir y que tiene relación con el cambio de uso del suelo 
agrícola durante este período es la que ofrecen los censos agropecuarios nacionales de 1964 y 1979 , que se presentan en el cuadro 3. En él podemos apreciar que de 1964 a 1973 desaparece el 53\% de las fincas subfamiliares medianas (de 30 se reducen a 16), las cuales dan paso a los primeros proyectos urbanísticos, que surgen especialmente en la ciudad de Quetzaltenango. Por otro lado, hay una atomización de las microfincas ya que se incrementan en un 150\%. También el número de fincas familiares y subfamiliares se reduce en un $60 \%$ y $50 \%$ respectivamente.

Para 1990 ocurre una reducción del uso agrícola en un 10,80\%. Esta reducción del área agrícola entre 1982 y 1990 coincide con dos acontecimientos ocurridos en el país que pudieron influenciar esta reducción: el flujo de inmigrantes que sufre la ciudad de Quetzaltenango, producto del desplazamiento provocado por el conflicto armado interno. Aunque no hay datos específicos sobre la inmigración a Quetzaltenango, de acuerdo con el informe de REMHI, ${ }^{3}$ este conflicto provocó una migración intermunicipal de 2052725 de habitantes, equivalente al $24,6 \%$ de la población existente, siendo la ciudad capital y Quetzaltenango las ciudades que más absorben dicha inmigración. Pero también coincide con el período en que prácticamente desaparece el sector público agrícola y la asistencia técnica agrícola gubernamental se reduce drásticamente. El cultivo de trigo pierde la protección arancelaria en el país, lo que provoca la desaparición casi por completo de este cultivo en el Valle de Quetzaltenango; esto desencadena una crisis en el sector agrícola que hace que para el agricultor sea más atractivo vender su terreno para fines urbanísticos que dedicarlo a la producción agropecuaria.

En el período 1990-2002 puede observarse también una reducción muy significativa del suelo con fines agrícolas, que representa el 21,9\% (2 I32 ha) con relación al área de 1964. Como puede apreciarse, del año 1964 a 1990 (26 años) desaparecen I,052 ha de suelos con fines agrícolas, que es muy similar al área que se pierde durante el período 1990-2002 (en tan solo 12 años), que fue de I 082 ha.
Este último período coincide con la construcción de la autopista de Los Altos, que da lugar a una franja de expansión urbana incontrolada en la periferia, que cubre una gran superficie de conversión territorial de suelo rural a urbano, dando lugar a proyectos urbanísticos con fines de vivienda y comercio alrededor de este eje vial. En este período también es ya significativo el crecimiento urbano de los municipios que conforman la Mancomunidad, especialmente La Esperanza y Olintepeque.

Pero la reducción más drástica de suelos con vocación agrícola ocurre del año 2002 al año 2006, cuando en un período de tan solo cuatro años desaparecen 2,I50 ha. Esta reducción representa prácticamente la misma área que se pierde de 1964 a 2002 (38 años), con 2132 ha. Para el año 2006, el uso del suelo con fines agrícolas ya solo ocupa el 28,9\% del área total de estudio, lo que en 1964 era del 51,5\%. Durante este período se acentúa el fenómeno de periurbanización y conurbación.

\section{Cambio de uso del territorio con vocación forestal}

De acuerdo con la información del cuadro I (capacidad de uso del suelo), el uso potencial con fines de aprovechamiento forestal de protección y de producción es de 6 617,89 ha (24,99\% del área total). En 1964, el uso del territorio con fines forestales y el área protegida era de 8317 ha. Para el año de inicio del estudio (1964), el área de uso forestal es de 5221 ha, que ocupa el 27,6\% del área total; para 1970 se han perdido 177 ha (26,7\%); para 1982 la pérdida fue de 412 ha y para 1990 ya eran 636 ha. Entre 1990 y 2002 ( 12 años) se pierden 792 ha, I 56 ha más de las que se perdieron entre 1964 y 1990 (26 años). Sin embargo, en el período 2002-2006 solo se pierden 46 ha de uso forestal, que es el equivalente al 0,2\% del área total, mientras que para el área agrícola fue del 1 I,6\% (ver figura 2).

El cambio de uso forestal a urbano ha sido más significativo que la pérdida del uso forestal a agrícola. La pérdida de la masa boscosa se ha dado especialmente en los alrededores del cerro El Baúl, cerro Candelaria, cerro Quemado y el volcán Siete Orejas. En este último, por ejemplo, se asienta la ciudad de los Altos, que ocupa terrenos en donde el uso adecuado es el de bosques de protección, por los servicios ambientales de esta área como zona de recarga hídrica para la ciudad de Quetzaltenango. 
Cuadro 3.Tamaño y número de fincas del área de estudio durante los años 1964 y 1979 de la Mancomunidad Metrópoli de Los Altos.

\begin{tabular}{|l|c|c|c|}
\hline \multicolumn{2}{|c|}{ Año } & 1964 & 1979 \\
\hline Microfincas & Tamaño finca & No. fincas & No. fincas \\
\hline Subfamiliares & $<1 \mathrm{MZ}$ & 5633 & 8428 \\
\hline Familiares & $1 \mathrm{Mz}$ a $<10 \mathrm{Mz}$ & 4456 & 2668 \\
\hline Multifamiliares medianas & $10 \mathrm{Mz} \mathrm{a}<64 \mathrm{Mz}$ & 214 & 106 \\
\hline \multicolumn{1}{|c|}{ TOTAL } & $1 \mathrm{Cab} a<120 \mathrm{cab}$ & 30 & 11218 \\
\hline
\end{tabular}

Fuente: INE, Censos agropecuarios de 1964 y 1979.

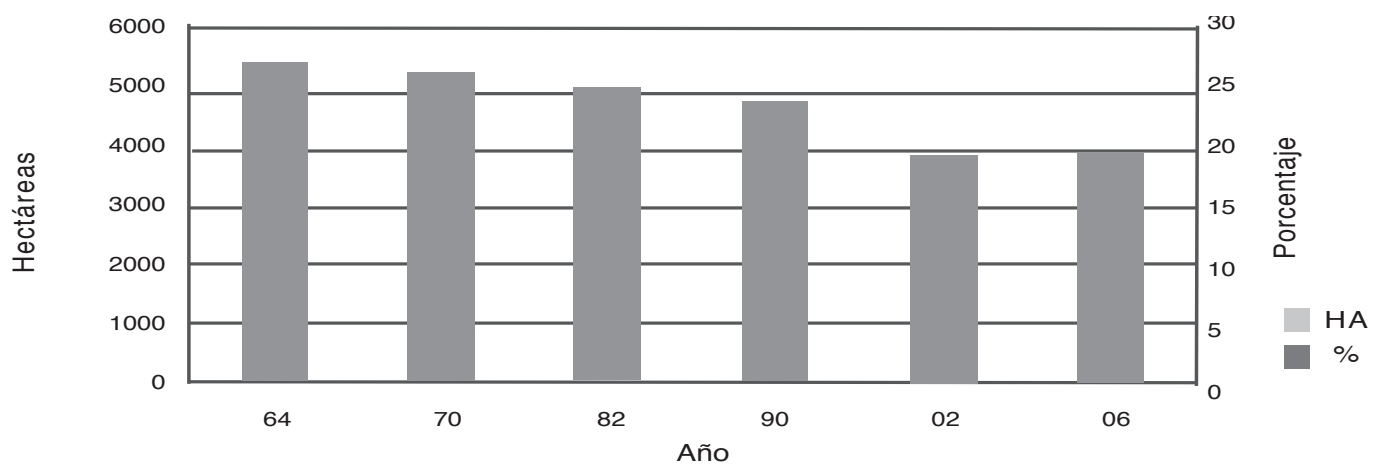

Figura 2. Reducción del uso forestal durante el periodo 1964-2006 en el área de estudio.

Fuente: investigación de campo 2010.

\section{Intensidad de uso de la tierra en el área de estudio}

la valoración de los conflictos de uso se hace sobre la base de comparar las categorías existentes de uso actual de la tierra, dándoles una calificación apreciativa en función de cada tipo de tierra presente en el municipio. La intensidad de uso resulta del contraste entre el mapa de uso potencial y uso actual del territorio (ver cuadro 4).

La valorización utilizada para determinar los conflictos de uso fue la siguiente: Uso correcto: Se asigna cuando en la confrontación existe un estado de equilibrio entre el uso actual y la capacidad de uso de la tierra, es decir, que se satisfacen los requerimientos entre la conservación y el desarrollo, y corresponde a la alternativa de mayor productividad en relación con el medio social local. Subuso: Esta categoría de confrontación se asigna cuando la tierra no es aprovechada eficientemente de acuerdo con su potencial productivo, el uso actual corresponde a una alternativa de menor productividad que la de la capacidad de uso. Sobreuso: Se fija esta designación cuando la tierra se utiliza con alternativas productivas que no son adecuadas de acuerdo con su potencial de uso, y presentan un alto riesgo para la degradación de los suelos y de los recursos naturales. Miscelánea: Está formada por aquellos usos que no aplican para las categorías anteriores y comprenden: caminos, carreteras, viviendas y lagunas o cuerpos de agua.

Para el caso del área de estudio en la Mancomunidad Metrópoli de Los Altos, las cifras de intensidad de uso son alarmantes porque más de la mitad del territorio está siendo sobreutilizada (5I,5\%), es decir, la actividad que se está realizando es de mayor intensidad de la que la tierra puede soportar, lo cual ocasiona baja productividad y degradación 
Cuadro 4. Conflictos (intensidad) de uso del territorio en la Mancomunidad Metrópoli de Los Altos, 2006.

\begin{tabular}{|c|c|c|}
\hline Categoría & Hectáreas & Porcentaje \\
\hline Uso adecuado & 1105 & 5,8 \\
\hline Subutilizado & 1464 & 7,7 \\
\hline Urbano & 6605 & 34,9 \\
\hline Sobreutilizado & 9745 & 51,5 \\
\hline Total & 18919 & 100,0 \\
\hline
\end{tabular}

Fuente: Investigación de campo 2009.

ambiental; por su parte, el suelo urbano ocupa el $34,7 \%$, el uso adecuado es de solo el $6,1 \%$ y el subutilizado el $7,7 \%$ del territorio en estudio.

\section{Escenario tendencial de los cambios de uso del suelo en el área de estudio}

de acuerdo con el patrón de comportamiento de los cambios de uso del suelo, especialmente la pérdida de suelos agrícolas y forestales ocasionada por el crecimiento de las áreas urbanas entre 1964 y 2006, se realizó un análisis de correlación múltiple para predecir el escenario tendencial, ${ }^{4}$ bajo la premisa de que las condiciones que generaron este comportamiento entre 1964 y 2006 se mantengan constantes, por lo que no se hace un análisis de los factores que pueden influenciar este cambio de uso del territorio.

En la figura 3 podemos apreciar que en el año 2006 el uso del suelo con fines urbanos (6 605 ha, 34,9\% del área total) ya ocupa un área superior al uso del suelo con fines agrícolas (5 47/ ha, 28,8\% del área total). De acuerdo con los resultados del análisis de correlación múltiple, podemos predecir que para el año 2014 el uso urbano ocupará un área de 7312 ha (38,56\% del área total), y que para el año 2039 el uso urbano ocupará un área de 12374 ha (65,25\% del área total), haciendo desaparecer por completo el suelo con fines agrícolas y reduciendo

4 Escenario tendencial: Corresponde a la extrapolación de tendencias. Lo que podría suceder si las cosas siguen comportándose como hasta ahora. el suelo con fines forestal a solo 3390 ha (17,86\%). Y para el año 2094 el área urbana hará también desaparecer en su totalidad el área boscosa de la región en estudio.

\section{Conclusiones}

de acuerdo con la capacidad de uso del suelo, en la Mancomunidad Metrópoli de Los Altos puede considerarse que casi en el 50\% del área de estudio el uso potencial del suelo es para actividades agrícolas sin limitaciones o con algunas prácticas de conservación de suelos; el 35\% para uso forestal de protección o de producción; por lo que de acuerdo con esta información solo el I 5\% de esta área tiene potencial para otros usos, en los que pueden incluirse centros poblados. Sin embargo, al contrastar la capacidad de uso del suelo con el uso del año 2006, podemos apreciar que existe una conflictividad (intensidad) de uso muy distante a esa capacidad, ya que solo el 5,8\% de esa área tiene un uso adecuado, el 7,7\% está subutilizado y el $51,5 \%$ está sobreutilizado, es decir, la intensidad del uso del suelo es mayor a la que soporta en términos físicos, lo que provoca baja productividad y una alta degradación ambiental.

Entre 1964 y 2006 pueden apreciarse los profundos cambios en el uso del suelo; donde destaca el fuerte crecimiento del área urbana (del 4,5\% a $34,9 \%$ del área total en estudio), en detrimento del área para uso forestal (del 27,6\% al 19,8\%), con alto valor como proveedor de servicios ambientales; y la reducción significativa del área para uso agrícola (de $51,5 \%$ a $28,9 \%$ ), suelos que se caracterizan por su alta vocación agrícola por ser planos, profundos, con buena textura y estructura, buen drenaje y alta fertilidad. El cambio de uso del territorio con vocación forestal ha sido más significativo con fines de uso habitacional que con fines agrícolas; es decir, la invasión de la mancha urbana en los suelos con vocación forestal ha sido más fuerte que la invasión de la frontera agrícola.

El incremento del área urbana entre 1990 y 2002 ha provocado el inicio del fenómeno de la conurbación, mediante el cual se eliminan los límites entre municipios, o estos no están bien definidos, lo que empieza a generar conflictos limítrofes.

De acuerdo con los resultados del análisis de correlación múltiple, el escenario tendencial que se puede predecir es que para el año 2034 el uso 


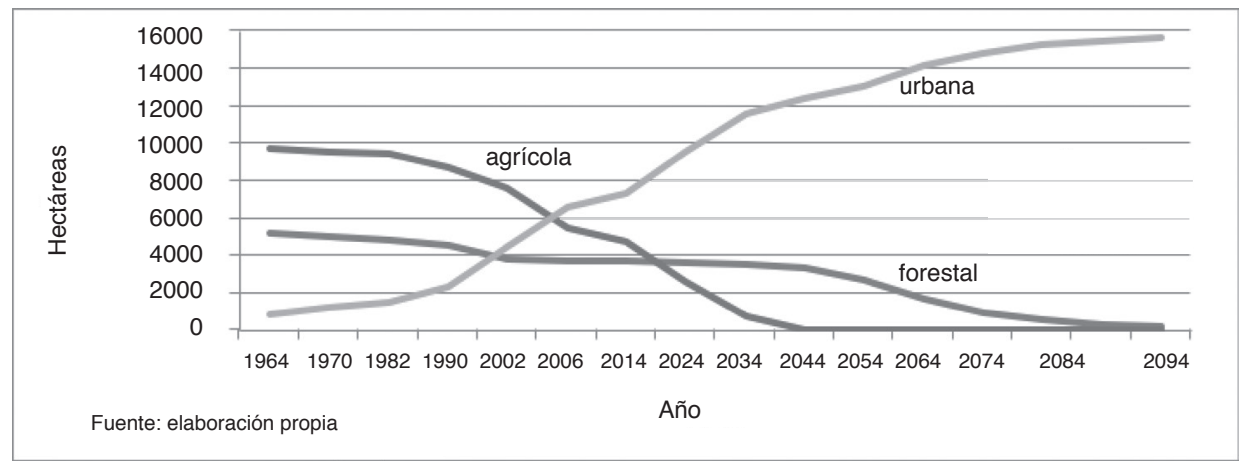

Figura 3. Comparación de los cambios de uso del suelo durante el periodo 1964-2006 en el área de estudio.

urbano ocupará un área de II 54I ha ( I I5,4I km²), haciendo desaparecer por completo el suelo con fines agrícolas y reduciendo aquel con fines forestal a solo 3390 ha.

Durante el período de estudio la densidad poblacional se ha reducido de manera significativa, ya que en 1964 en las áreas urbanas ésta era de 9011 habitantes por $\mathrm{km}^{2}$ y para 2006 se reduce a 3199 habitantes por $\mathrm{km}^{2}$. Esta reducción puede deberse a diferentes fenómenos, entre los cuales están: cambios de uso del suelo urbano (áreas que antes eran para uso habitacional hoy son ocupadas por actividades comerciales, desplazando esta población a nuevas áreas urbanas), especulación (es decir, la inversión en vivienda no responde a las necesidades de la población sino a la especulación inmobiliaria), lavado de dinero, ausencia de regulaciones en el uso del suelo y la tendencia predominante del desarrollo horizontal de la vivienda.

\section{Bibliografía}

Alvarado Quiroa, H. (20I0). Análisis del crecimiento urbano y los cambios de uso del suelo durante el período 1964-2006, y propuesta de Unidades Territoriales en los municipios conurbados de la Mancomunidad Metrópoli de Los Altos, Quetzaltenango. Tesis MSc. Facultad de Agronomía, Universidad de San Carlos de Guatemala. 97 pp.

Ávila Rangel, J. (2005). El control del crecimiento urbano con la ayuda del catastro y del plan de ordenamiento del territorio: estudio del caso de Guanajuato. Tesis MSc. Geomatiques. Francia, Université Laval, Faculté de Foresterie et de Gémotique. 173 pp.

Azócar, G. \& Sanhuenza, R. (2003). La incidencia de factores regionales y locales en el crecimiento urbano de Chillan. Chile, Universidad del Bío Bío. 148 pp.
Bazant, J. (200 I). Lineamientos para el ordenamiento territorial de las periferias urbanas de la ciudad de México (en línea). México, Universidad Autónoma Metropolitana-Xochimilco. Consultado 5 ene. 2007. Disponible en:_http://www.e-local. gob.mx/wb2

CONAP (Consejo Nacional de Áreas Protegidas, GT), PROPETEN (Proyecto ProPetén, GT). (200 I). Plan de ordenamiento territorial, unidad de manejo Buen Samaritano, Parque Nacional Laguna del Tigre, San Andrés, Petén, Guatemala. 164 pp.

Congreso Nacional de la República de Guatemala, GT. (1989). Ley de áreas protegidas, Decreto No. 4-89. 16 p.

Congreso Nacional de la República de Guatemala, GT. (1997). Ley reguladora de las áreas de reserva territoriales del estado de Guatemala, Decreto No. 126-97. 8 pp.

Congreso Nacional de la República de Guatemala, GT. (2005). Ley de registro de información catastral, Decreto No. 4|-2005. 33 pp.

Gómez Orea, D. (2002). Ordenación del territorio. Instituto Tecnológico Geominero de España-Editorial Agrícola Española. p. 1-17, 25-32.

Hernández, D. \& López Blanco, J. (2000). Producción e integración de fotomapas digitales para la evaluación del crecimiento urbano en el municipio de Texcoco, estado de México: período 1970-| 989-| 997. UNAM, Instituto de Geografía. Boletín no. 42: 48-66.

Herrera, V. (200I). Estudio del crecimiento urbano de la ciudad de Valdivia (Chile), a través del uso integrado de imágenes de satélites, SIG y equipos GPS. Universidad de Santiago de Chile. $180 \mathrm{Pp}$.

INAB (Instituto Nacional de Bosques, GT). (2000). Clasificación de tierras por capacidad de uso, aplicación de una metodología para tierras de la República de Guatemala. 96 pp.

INE (Instituto Nacional de Estadística, GT). (1996). X censo nacional de población y $\vee$ de habitación, Departamento de Quetzaltenango 1994. Guatemala. p. 32.

INE (Instituto Nacional de Estadística, GT). (2002). XI censo nacional de población y VI de habitación, 2002. (en línea). Guatemala. Consultado 5 ene 2008. Disponible en: http:// www.ine.gob.gt/index.php/demografia-y-poblacion/42demografiaypoblacion/75-censo2002 